This item was submitted to Loughborough's Institutional Repository (https://dspace.lboro.ac.uk/) by the author and is made available under the following Creative Commons Licence conditions.

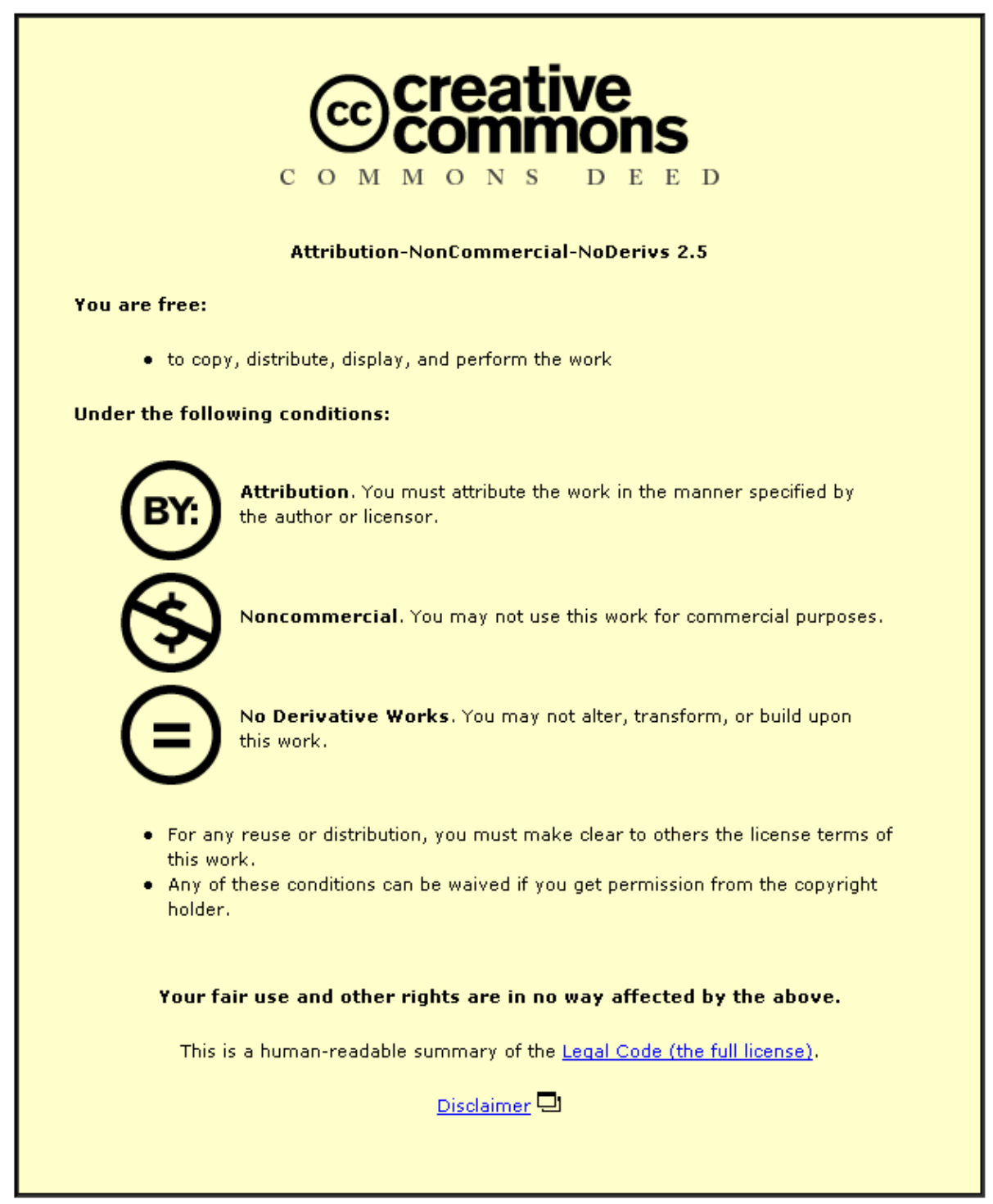

For the full text of this licence, please go to: http://creativecommons.org/licenses/by-nc-nd/2.5/ 


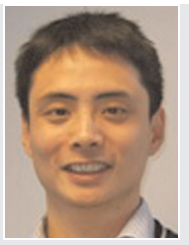

Bo Zhang Geotechnical Engineer, Golder Associates (UK) Ltd, Stanton-on-theWolds, UK
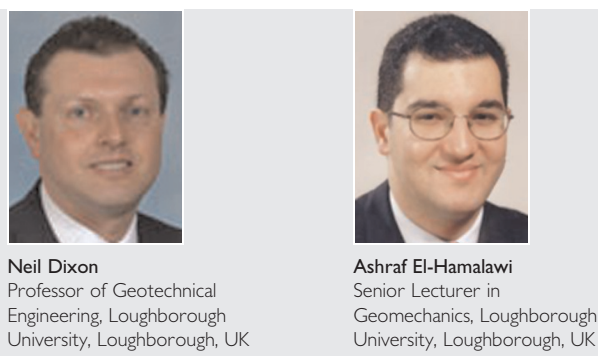

\section{Development and evaluation of a phase relationship for MSW}

B. Zhang MSc, PhD, N. Dixon PhD, fGS and A. El-Hamalawi PhD, MASCE, MCGS, MILT, PEng

Compression is one of the most important mechanical aspects of behaviour of municipal solid waste (MSW) which concerns stability, deformation and structural performance in a landfill. Previous studies have shown that compressible particles play a significant role in MSW compression. Definition of the void ratio in classical soil mechanics theory may no longer be applicable for MSW material since high non-linearity between void ratio changes and vertical stress changes have been identified in compression tests. A new phase relationship for MSW has been developed to include the volume loss of compressible particles and this has been evaluated using onedimensional compression test data. The comparison between analytical and test results has demonstrated that the MSW phase relationship is capable of analysing the volume losses originated from inter- and intra-void ratio changes, in addition to the total volume loss of the MSW sample under different vertical stresses. Since it can isolate the volumetric change of compressible particles from the total volume loss, the MSW phase relationship is important when developing a constitutive model for MSW assuming elasto-plastic material behaviour, which couples the volumetric and shear behaviour.

\section{NOTATION}

$\mathrm{C}_{\mathrm{C}} \quad$ compression index

$C_{\mathrm{C}-\text { Inter }}$ inter-compression index

$C_{\mathrm{C}-\text { Intra }}$ intra-compression index

e void ratio (or inter-void ratio)

$e_{0} \quad$ initial void ratio before compression

$e_{1} \quad$ void ratio after compression

$f \quad$ intra-void ratio

$H_{0} \quad$ original height of the one-dimensional (1D) compression sample

$\Delta H \quad$ vertical displacement in $1 \mathrm{D}$ compression

$n_{\mathrm{e}} \quad$ drainage porosity

$\mathbf{p} \quad$ vertical stress in $1 \mathrm{D}$ compression test

$\boldsymbol{p}_{0} \quad$ initial vertical stress in 1D compression test

$V_{\mathrm{I}} \quad$ total potential incompressible volume

$V_{\mathrm{S}} \quad$ volume of waste particles

$V_{\mathrm{V}} \quad$ volume of voids between waste particles

$V_{\mathrm{V}-\text { Inter }}$ inter-void volume

$V_{\mathrm{V}-\text { Intra }} \quad$ intra-void volume

$v \quad$ specific volume

$W C_{\mathrm{vol}} \quad$ water content at field capacity

\section{INTRODUCTION}

Solid-water-air volume and weight relationships are essential in soil mechanics as they form the basis for defining soil physical properties such as void ratio, unit weight, water content, etc. These are strongly linked to mechanical properties that are normally expressed in terms of physical properties. For instance, soil compressibility and consolidation are expressed as the compressibility of voids between solid particles. Equation 1 shows the vertical displacement of a soil sample under one-dimensional (1D) compression stress conditions (e.g. oedometer test)

$$
\text { । } \Delta H=\frac{e_{0}-e_{1}}{1+e_{0}} H_{0}
$$

where $H_{0}$ is the original height of the sample, and $e_{0}$ and $e_{1}$ are the initial and new void ratios, respectively (Taylor, 1948). Equation 1 assumes that the solid phase in the soil is volumetrically incompressible - that is, only void volume change is accountable for the compressibility and consolidation. This is a reasonable assumption for the majority of soil materials (both fine and coarse grained) as the compressibility of the solid phase is usually very small in comparison with that of the void phase so that it can be ignored in the analysis. Nevertheless, applying the same assumption to materials in which the compressibility of the solid phase is not negligible could prove problematic. Municipal solid waste (MSW) material lies in this category.

The study of MSW as an engineering material has been ongoing for several decades with the aim of predicting landfill settlement (e.g. Edil et al., 1990; Ling et al., 1998; McDougall and Pyrah, 2004), waste mass slope stability (e.g. Eid et al., 2000; Singh and Murphy, 1990; Zhan et al., 2008) and its effect on landfill liner stability (e.g. Dixon et al., 2004; Fowmes et al., 2005). The waste body is the largest element in a landfill and hence it affects a number of structural performance-related issues - the side slope lining system in particular (Dixon et al., 2004). It is therefore necessary to investigate and characterise the mechanical behaviour of MSW.

To date, classical soil mechanics principles have been applied to studies of MSW, with its mechanical behaviour treated as being comparable to that of soil material. For example, primary and secondary compression indices have been used as MSW compressibility parameters to predict landfill settlement (Edil et al., 1990; Landva et al., 2000). Moreover, soil constitutive models 
have been widely adopted for MSW in landfill-related numerical modelling (Bryne, 1994; Filz et al., 2001; Fowmes et al., 2005; Jones and Dixon, 2005; Long et al., 1995; Meißner and Abel, 2000; Reddy et al., 1996). However, with increasing demands to simulate the mechanical response of MSW (particularly in numerical modelling), an advanced understanding of how such waste reacts to external forces is needed. There is thus a need
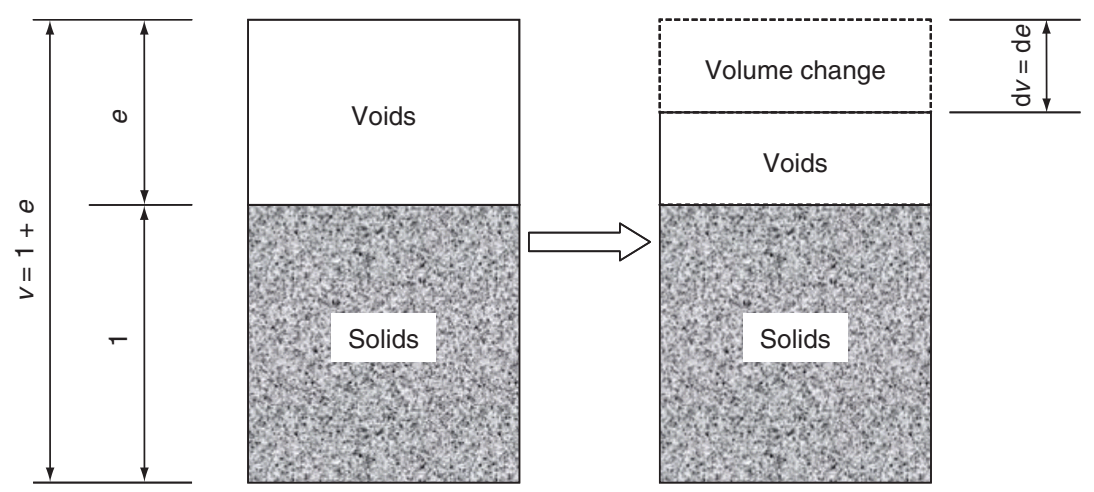

Figure I. Phase relationship for soil

to develop constitutive

relationships for MSW material (Zhang, 2007). McDougall and Pyrah (2004) proposed a phase relationship for decomposable soils, and this was applied to analyse landfill settlements due to biodegradation of MSW (McDougall and Hay, 2005). However, compressible particles were not considered in this phase relationship.

This paper discusses and demonstrates the influence of compressible particles in MSW on its mechanical behaviour by considering MSW compression test results reported in the literature (Langer, 2006; Powrie and Beaven, 1999). A phase relationship for MSW is proposed by including compressible particles in the classical soil phase relationship and this is applied to the boundary condition of a $1 \mathrm{D}$ compression test. The proposed MSW phase relationship is evaluated by analysing the compression test data reported by Powrie and Beaven (1999).

\section{COMPRESSIVE BEHAVIOUR OF MSW}

One-dimensional compression tests have been carried out on real and artificial MSW samples to investigate volume change behaviour (Landva et al., 2000; Langer, 2006; Powrie and Beaven, 1999). Most of these tests were conducted under drained conditions and over a short time period so that significant biodegradation would not have occurred. Due to the larger particle sizes in MSW and its heterogeneity, MSW compression tests usually use larger samples than are commonly used in normal soil tests. Most compression test results in the literature show an almost linear relationship between the instant waste volume change and the logarithm of the effective vertical stress, which is comparable to the instant compressive behaviour of soils. It is for this reason that the definition of coefficient of compression from soil compressibility has so far been used by researchers and practitioners to represent MSW compressibility and then used to analyse primary landfill settlement.

MSW usually comprises a great many compressible components from household refuse (e.g. plastic packaging, cans and boxes).

Langer (2006) conducted a series of compression tests on so-called synthetic wastes consisting of ranges of percentages of paper, plastic bags, aluminium cans, plastic packaging and sand. Eight different samples of varying waste compositions were prepared and compressed in a large compression cell of total volume $0 \cdot 1875 \mathrm{~m}^{3}$ (length $0.5 \mathrm{~m}$, width $0.5 \mathrm{~m}$, height $0.75 \mathrm{~m}$ ). Photographs taken throughout the test (Dixon et al., 2008) revealed that all the compressible components experience compression (i.e. volume reduction of the components).
Powrie and Beaven (1999) conducted 1D compression tests on unprocessed UK household waste in a large compression cell $(2 \mathrm{~m}$ diameter, height $3 \mathrm{~m}$ ). Detailed test data were reported for a specific waste sample called DM3, including total sample volumes and void ratio values at different vertical stresses. To the best of the authors' knowledge, this is the first and only reported attempt to measure void ratio of a compressed waste sample, and hence is the primary source of information available for use in evaluating a new phase relationship for MSW. The results showed that the curve of vertical strain against the logarithm of vertical stress has an almost linear relationship, which is identical to observed soil compressive behaviour, while the void ratio curve showed a very highly non-linear relationship. Powrie and Beaven (1999) attributed this to the existence of compressible particles in the MSW sample. In fact, volume compression of these particles was identified in the test, but further investigations have not been carried out. (This finding is considered further in Section 6.) The non-linearity and volume loss of solid particles imply that the traditional definition of void ratio in soil mechanics theory may not be applicable to MSW. Relevant amendments are thus required to include the influence of compressible particles on MSW behaviour.

\section{PROPOSAL OF MSW PHASE RELATIONSHIP}

In the soil phase relationship, solid particle volume is assumed to be constant (i.e. incompressible) so that it can be set as unity in the phase relationship analysis. Therefore, the specific volume $v$ can be expressed as

\begin{tabular}{|l|l|}
\hline 2 & $v=1+e$ \\
\hline
\end{tabular}

where $e$ is the void ratio, defined as the ratio of void volume to the solid particle volume. It should be noted that water and/or air could exist in the voids, and there is no intention of separating water and air voids in this paper. The simplified phase relationship for soil is depicted in Figure 1.

The total volume change due to external stress (e.g. 1D compression) is only due to the volume change of the void in accordance with

\begin{tabular}{|l|l|}
\hline 3 & $\mathrm{~d} v=\mathrm{de}$ \\
\hline
\end{tabular}

For waste material that includes compressible particles, it is proposed to separate the voids into two different types, inter-void 
and intra-void. The notion of inter- and intra-voids was first introduced by Landva and Clark (1990) who defined intervoids as the voids between waste particles and intra-voids the voids within waste particles.

While it appears to be appropriate to fix the incompressible particles' volume as constant, compressible particles can be converted into incompressible particles over a threshold stress, and therefore it is more reasonable to define the total potential incompressible volume (including the final volume of compressible particles and volume of incompressible particles) as constant. The potential incompressible volume is suggested to be simply considered as the pure material volume and is calculated through material density of the particles in the current study. Future studies can be undertaken to link this volume with the maximum stress that the material will experience.

Consequently, the additional parameter of intra-void ratio $f$ is introduced to describe the ratio of void volume within waste particles to the total potential incompressible volume

\begin{tabular}{|l|l|}
\hline 4 & $f=\frac{V_{\mathrm{V}-\text { Intra }}}{V_{\mathrm{I}}}$ \\
\hline
\end{tabular}

where $V_{\mathrm{I}}$ is the total potential incompressible volume and $V_{\mathrm{V} \text {-Intra }}$ is the volume of intra-voids. The inter-void ratio $e$ (the ratio of void volume between waste particles to the total potential incompressible volume) is similar to the conventional soil void ratio

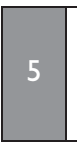

$$
e=\frac{V_{\mathrm{V}-\text { Inter }}}{V_{\mathrm{I}}}
$$

where $V_{\mathrm{V}-\text { Inter }}$ is the volume of inter-voids. The waste-specific volume can thus be defined as

\begin{tabular}{|l|l|}
\hline 6 & $v=1+e+f$ \\
\hline
\end{tabular}

The total volume change can be obtained by differentiating

\begin{tabular}{|l|l|}
\hline 7 & $\mathrm{~d} v=\mathrm{d} e+\mathrm{d} f$ \\
\hline
\end{tabular}

which means that waste volume change comes from both intervoid ratio change and intra-void ratio change, as shown in Figure 2.

\section{ONE-DIMENSIONAL COMPRESSION ANALYSIS}

Volume change due to conventional void compression and that due to particle compression can be calculated separately from inter-void and intra-void ratio changes based on the proposed phase relationship. The proposed MSW phase relationship is applied to 1D compression conditions that establish the relationship between external forces and volume loss. The intervoid ratio change under $1 \mathrm{D}$ compression can be expressed as

$$
\mathrm{d} e=C_{\mathrm{C}-\mathrm{Inter}} \log \frac{\boldsymbol{p}_{0}+\mathrm{d} \boldsymbol{p}}{\mathbf{p}_{0}}
$$

where $C_{\mathrm{C}-\text {-Inter }}$ is the inter-compression index (similar to the compression index in soil mechanics). The intra-void ratio change $\mathrm{d} f$ is defined as

$9 \quad \mathrm{~d} f=C_{\mathrm{C}-\text { Intra }} \log \frac{\boldsymbol{p}_{0}+\mathrm{d} \boldsymbol{p}}{\boldsymbol{p}_{0}}$

where $C_{\mathrm{C}-\text { Intra }}$ is the intra-compression index. Therefore, the total volume change can be calculated by adding the two parts of volume change together

$$
10 \quad \mathrm{~d} v=\left(C_{\text {C-Inter }}+C_{\text {C-Intra }}\right) \log \frac{\mathbf{p}_{0}+\mathrm{d} \mathbf{p}}{\mathbf{p}_{0}}
$$

Both inter- and intra-void ratio changes have been assumed to be linear with logarithm stress level in the 1D compression model, and therefore the total volume change will also be linear as observed in tests on MSW.

\section{EVALUATION OF MSW PHASE RELATIONSHIP}

Household waste sample DM3 (Powrie and Beaven, 1999) was obtained directly from the tipping face of a UK landfill. Data under different vertical stresses were obtained and presented, including dry density, drainable porosity, water content at field capacity and saturated hydraulic conductivity. Before every loading step, the sample in the cell was flushed with water and then left to drain freely. The water content at field capacity $W C_{\text {vol }}$ (i.e. after free drainage) and drainage porosity $n_{\mathrm{e}}$ could then be measured. The specific volume $v$ can be determined from (Powrie and Beaven, 1999)

। $v=\frac{V_{\mathrm{S}}+V_{\mathrm{V}}}{V_{\mathrm{S}}}=\frac{1}{1-\left(W C_{\mathrm{vol}}+n_{\mathrm{e}}\right)}$

where $V_{\mathrm{S}}$ is the volume of waste particles and $V_{\mathrm{V}}$ is the volume of voids between the waste particles.

Therefore, the void ratio calculated from this specific volume expression has included the influence of volume change of waste 


\begin{tabular}{|lcccccccc|}
\hline $\begin{array}{l}\text { Vertical } \\
\text { stress: } \\
\mathrm{kPa}\end{array}$ & $\begin{array}{c}\text { Cell } \\
\text { volume: } \\
\mathrm{m}^{3}\end{array}$ & $\begin{array}{c}\text { Void } \\
\text { volume: } \\
\%\end{array}$ & $\begin{array}{c}\text { Void } \\
\text { volume: } \\
\mathrm{m}^{3}\end{array}$ & $\begin{array}{c}\text { Solid } \\
\text { volume: } \\
\mathrm{m}^{3}\end{array}$ & $\begin{array}{c}\text { Tested } \\
\text { void } \\
\text { ratio }\end{array}$ & $\begin{array}{c}\text { Assumed } \\
\text { voids } \\
\text { volume: } \mathrm{m}^{3}\end{array}$ & $\begin{array}{c}\text { Assumed } \\
\text { solids } \\
\text { volume: } \mathrm{m}^{3}\end{array}$ & $\begin{array}{c}\text { Calculated } \\
\text { void } \\
\text { ratio }\end{array}$ \\
\hline 34 & 6.851 & 55.5 & 3.802 & 3.049 & 1.247 & 3.802 & 3.049 & 1.247 \\
65 & 6.214 & 55.6 & 3.455 & 2.759 & 1.252 & 3.165 & 3.049 & 1.038 \\
120 & 5.344 & 51.0 & 2.725 & 2.619 & 1.041 & 2.295 & 3.049 & 0.753 \\
241 & 4.310 & 47.0 & 2.026 & 2.284 & 0.887 & 1.261 & 3.049 & 0.414 \\
463 & 3.763 & 45.5 & 1.712 & 2.051 & 0.835 & 0.714 & 3.049 & 0.234 \\
& & & & & & & &
\end{tabular}

Table I. Calculation of void ratios assuming solid particles are incompressible in DM3

particles as shown in Table 1 (column 5). This is different to the definition of the conventional void ratio in soil mechanics as it is based on a constant solid phase volume, which explains why the relationship between void ratio and effective stress (logarithm) from the test shown in Figure 3 has demonstrated a highly nonlinear trend (real test data curve). By assuming the solid particles in this waste sample to be incompressible (i.e. fixing the volume of solid particles to be $3.049 \mathrm{~m}^{3}$ (as in Table 1)) and recalculating the change of void ratio from vertical strain of the sample, the curve changes to an almost linear relationship, as shown in Figure 3

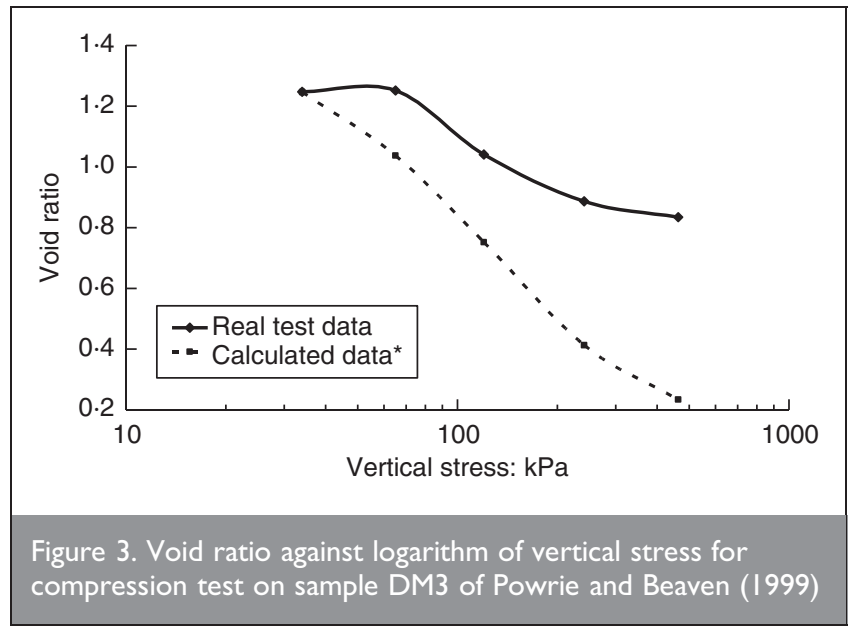

(curve labelled calculated data). This calculation shows that the definition of void ratio used in soil mechanics, which is based on a constant solid particle volume, is not appropriate to represent the volume change behaviour of MSW.

It is possible to separate the volumetric change due to the compression of particles (intra-void compression) from that due to particle movement and rearrangement (inter-void compression) from the test results of DM3, which can then be used to evaluate the proposed MSW phase relationship. In Figure 4, the volumetric change of compressible particles (solids volume) and inter-voids have been separated directly from the test data presented in Table 2, and plotted together with the total volume change under different vertical stresses. It appears that volumetric changes for both compressible particles and inter-voids under different vertical stresses (logarithm) show a very similar trend to the total volume change, which is also linear.

The void volume obtained in the DM3 test data should include the volume of all the inter-voids and possibly some of the volume of the intra-voids, subject to their status. The status of the intra-voids in MSW can either be closed (e.g. plastic bottles with caps on) or open (e.g. used aluminium cans). Assuming all the intra-particle voids are closed (i.e. water cannot flow through these voids), the calculated void ratio should only be the inter-void ratio. Assuming all the intra-particle voids are open (i.e. water can flow in and out of the voids), the calculated

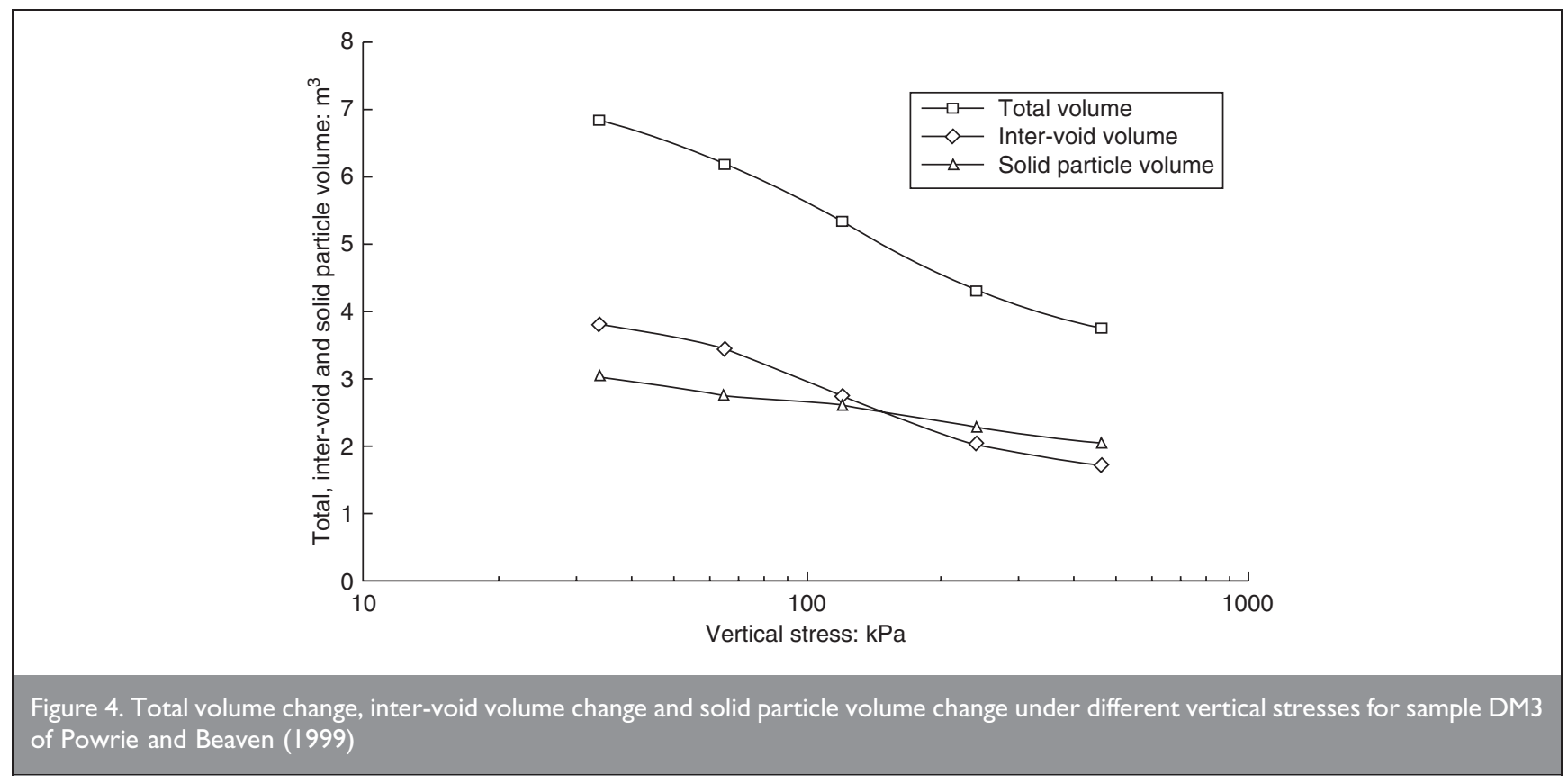




\begin{tabular}{|c|c|c|c|c|c|c|c|}
\hline \multirow{2}{*}{$\begin{array}{l}\text { Vertical stress: } \\
\mathrm{kPa}\end{array}$} & \multirow{2}{*}{$\begin{array}{l}\text { Dry density: } \\
\qquad \mathrm{Mg} / \mathrm{m}^{3}\end{array}$} & \multirow{2}{*}{$\begin{array}{l}\text { Specific } \\
\text { volume, } v\end{array}$} & \multirow{2}{*}{$\begin{array}{l}\text { Percentage of } \\
\text { void volume: \% }\end{array}$} & \multirow{2}{*}{$\begin{array}{l}\text { Inter-void } \\
\text { ratio, e }\end{array}$} & \multirow{2}{*}{$\begin{array}{l}\text { Intra-void } \\
\text { ratio, } f\end{array}$} & \multicolumn{2}{|c|}{ Conventional void ratio } \\
\hline & & & & & & Calculated & From test data \\
\hline I & 0.33 & $4 \cdot 848$ & - & - & - & - & - \\
\hline 34 & 0.39 & $4 \cdot 103$ & $55 \cdot 5$ & $2 \cdot 277$ & 0.826 & $1 \cdot 247$ & $\mid \cdot 247$ \\
\hline 65 & 0.43 & $3 \cdot 721$ & $55 \cdot 6$ & 2.069 & 0.652 & $1 \cdot 252$ & $1 \cdot 252$ \\
\hline 120 & 0.50 & $3 \cdot 200$ & 51.0 & 1.632 & 0.568 & $|.04|$ & $|.04|$ \\
\hline 241 & 0.62 & $2 \cdot 581$ & $47 \cdot 0$ & 1.213 & 0.368 & 0.887 & 0.887 \\
\hline 463 & 0.71 & $2 \cdot 254$ & $45 \cdot 5$ & 1.025 & 0.228 & 0.835 & 0.835 \\
\hline
\end{tabular}

void ratio should include both inter- and intra-voids. Assuming only a proportion of the intra-particle voids are open, the calculated void ratio includes the inter-void ratio and a proportion of the intra-void ratio. It is, however, not possible to identify the proportion of the intra-void ratio for DM3 at this stage. It is thus proposed to examine and analyse two different cases assuming different statuses of intra-voids in DM3.

(a) Case 1: all intra-voids are closed, which means the calculated void ratio from the test data equals the inter-void ratio.

(b) Case 2: 30\% of the intra-voids are open, which means the calculated void ratio from the test data consists of both inter- and intra-void ratios.

\section{I. Case I}

Specific volume and void ratio values from the tests were processed in accordance with the proposed MSW phase relationship. The density of the waste particles was assumed to be $1.6 \mathrm{Mg} / \mathrm{m}^{3}$, as estimated by Langer (2006) for synthetic wastes. The specific volume can then be calculated by the assumed waste particle density $\left(1.6 \mathrm{Mg} / \mathrm{m}^{3}\right)$ divided by the dry density. The amended values of specific volume, void ratios (including both inter- and intra-void ratios) under different vertical stresses are presented in Table 2 . The conventional void ratios can be backcalculated from the known void volume. It can be seen from Table 2 (last 2 columns) that the calculated conventional void ratios are identical to the ratios obtained directly from the test data that were used to calibrate the analysis. Specific volume, inter-void ratio and intra-void ratio calculated from the test data are plotted in Figure 5 (solid lines) under different vertical stress levels.

The 1D compression case was then applied to analyse the void ratios, void and particle volumes, and vertical strain based on the proposed MSW phase relationship. Four parameters are needed specific volume under unit stress $v_{0}$, inter-void ratio under unit stress $e_{0}$, inter-compression index $C_{\mathrm{C}-\text { Inter }}$ and intra-compression index $C_{\mathrm{C} \text {-Intra. }}$. These parameters were back-analysed from the test curves (Figure 5) and are given in Table 3.

The specific volume, inter-void ratio and intra-void ratio were calculated by applying the MSW phase relationship as shown in Table 4; the results are plotted in Figure 5 along with the test curves. It can be seen from the figure that the trends of all three values are well predicted by the approach based on the proposed

\begin{tabular}{|lccccc|}
\hline & $v_{0}$ & $e_{0}$ & $f_{0}$ & $C_{\text {C-Inter }}$ & $C_{\text {C-Intra }}$ \\
\hline Case I & 7 & 4.2 & 1.8 & $1 \cdot 2$ & 0.6 \\
Case 2 & 7 & 3.3 & 2.7 & 0.9 & 0.9 \\
\multicolumn{5}{l}{ Table 3. Parameters selected for ID compression analysis } \\
\hline
\end{tabular}

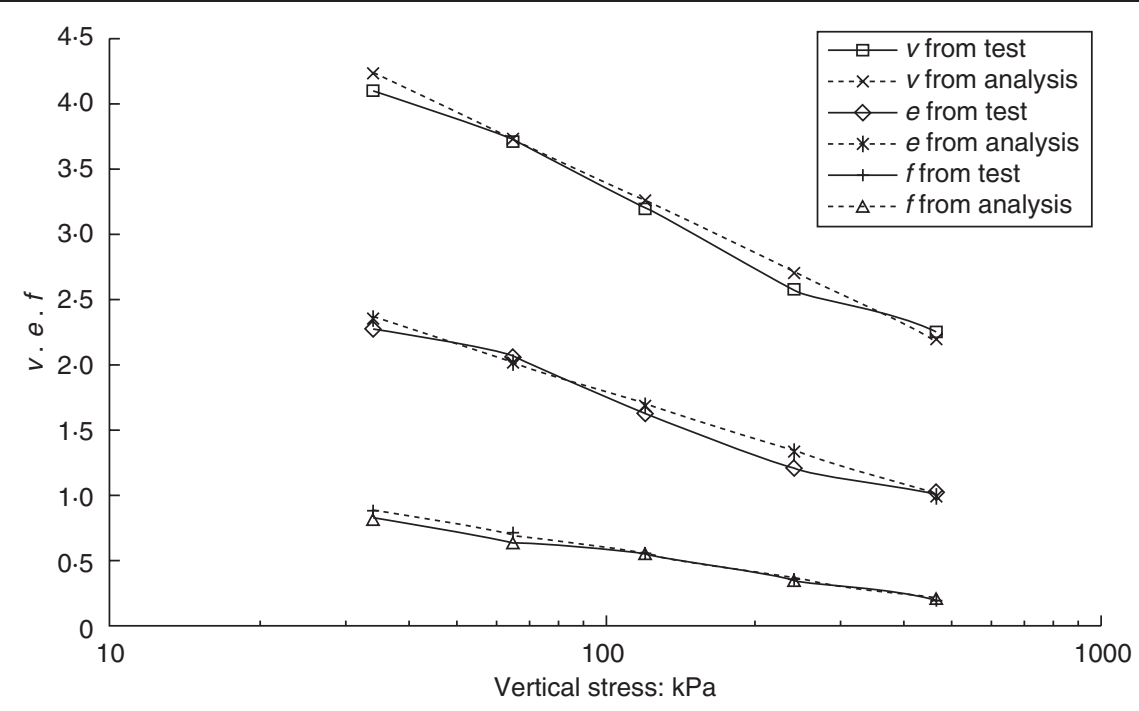

Figure 5. Specific volume, inter-void ratio, intra-void ratio under different vertical stresses obtained from test and ID compression analysis for case I 


\begin{tabular}{|c|c|c|c|c|c|c|c|c|}
\hline $\begin{array}{l}\text { Vertical stress: } \\
\mathrm{kPa}\end{array}$ & $\begin{array}{l}v \text { from } \\
\text { model }\end{array}$ & $\begin{array}{l}\text { e from } \\
\text { model }\end{array}$ & $\begin{array}{l}f \text { from } \\
\text { model }\end{array}$ & $\begin{array}{c}\text { Total volume: } \\
\mathrm{m}^{3}\end{array}$ & $\begin{array}{l}\text { Inter-void } \\
\text { volume: } \mathrm{m}^{3}\end{array}$ & $\begin{array}{l}\text { Intra-void } \\
\text { volume: } \mathrm{m}^{3}\end{array}$ & $\begin{array}{l}\text { Solids } \\
\text { volume: } \mathrm{m}^{3}\end{array}$ & $\begin{array}{l}\text { Vertical } \\
\text { strain: \% }\end{array}$ \\
\hline I & 7.000 & $4 \cdot 200$ & 1.800 & - & - & - & - & - \\
\hline 34 & $4 \cdot 243$ & $2 \cdot 362$ & 0.881 & 6.851 & $3 \cdot 814$ & 1.423 & 3.037 & 15.4 \\
\hline 65 & 3.737 & 2.025 & 0.712 & 6.033 & $3 \cdot 269$ & $1 \cdot 150$ & $2 \cdot 764$ & $25 \cdot 5$ \\
\hline 120 & $3 \cdot 257$ & 1.705 & 0.552 & $5 \cdot 259$ & $2 \cdot 753$ & 0.892 & $2 \cdot 507$ & $35 \cdot 0$ \\
\hline 241 & $2 \cdot 712$ & $\mid \cdot 342$ & 0.371 & $4 \cdot 379$ & $2 \cdot 166$ & 0.599 & $2 \cdot 213$ & 45.9 \\
\hline 463 & $2 \cdot 202$ & 1.001 & 0.201 & 3.555 & 1.617 & 0.324 & 1.938 & $56 \cdot 1$ \\
\hline
\end{tabular}

MSW phase relationship. In addition, comparisons between test and predicted results were also carried out for particle and void volumes, and vertical strains under different vertical stresses (Figures 6 and 7, respectively).

\subsection{Case 2}

The calculated values of void ratio (i.e. assuming 30\% intra-voids are open) are presented in Table 5 and the results are plotted in
Figure 6 (solid lines). The 1D compression analysis was then applied to this case based on the proposed MSW phase relationship (Table 6).

Figure 8, which presents the 1D compression analysis data together with test curves for case 2 , shows that the volume changes of both inter- and intra-voids predicted by the analysis are close to those obtained from the test. Curves of particle and
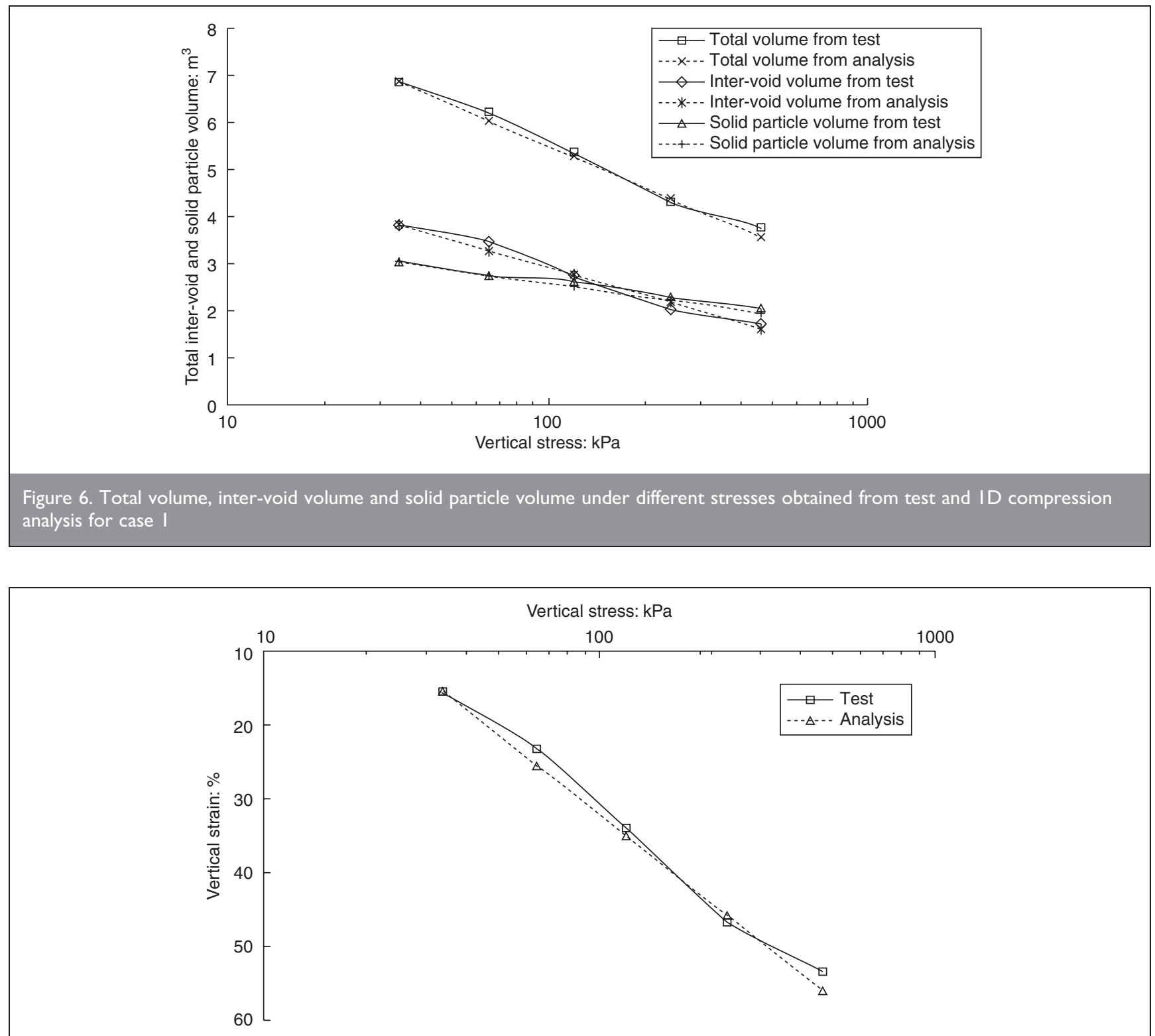

Figure 7. Vertical strains under different vertical stresses obtained from test and ID compression analysis for case I 


\begin{tabular}{|c|c|c|c|c|c|c|c|}
\hline $\begin{array}{l}\text { Vertical stress: } \\
\mathrm{kPa}\end{array}$ & $\begin{array}{l}\text { Dry density: } \\
\qquad \mathrm{Mg} / \mathrm{m}^{3}\end{array}$ & $\begin{array}{l}\text { Specific } \\
\text { volume, } v\end{array}$ & $\begin{array}{l}\text { Percentage of inter-voids } \\
\text { plus open intra-voids: } \%\end{array}$ & $\begin{array}{l}\text { Open intra-void } \\
\text { ratio }\end{array}$ & $\begin{array}{c}\text { Closed intra-void } \\
\text { ratio }\end{array}$ & $\begin{array}{l}\text { Intra-void } \\
\text { ratio, } f\end{array}$ & $\begin{array}{l}\text { Inter-void } \\
\text { ratio, e }\end{array}$ \\
\hline I & 0.33 & 4.848 & - & - & - & - & - \\
\hline 34 & 0.39 & $4 \cdot 103$ & $55 \cdot 5$ & 0.354 & 0.826 & $1 \cdot 180$ & 1.923 \\
\hline 65 & 0.43 & 3.721 & $55 \cdot 6$ & 0.279 & 0.652 & 0.931 & 1.790 \\
\hline 120 & 0.5 & $3 \cdot 200$ & 51.0 & 0.243 & 0.568 & 0.811 & $1 \cdot 389$ \\
\hline 241 & 0.62 & $2 \cdot 581$ & $47 \cdot 0$ & 0.158 & 0.368 & 0.526 & 1.055 \\
\hline 463 & 0.71 & $2 \cdot 254$ & $45 \cdot 5$ & 0.098 & 0.228 & 0.326 & 0.928 \\
\hline
\end{tabular}

\begin{tabular}{|c|c|c|c|c|c|c|c|c|}
\hline $\begin{array}{l}\text { Vertical stress: } \\
\mathrm{kPa}\end{array}$ & $\begin{array}{l}v \text { from } \\
\text { model }\end{array}$ & $\begin{array}{l}\text { e from } \\
\text { model }\end{array}$ & $\begin{array}{l}f \text { from } \\
\text { model }\end{array}$ & $\begin{array}{l}\text { Total } \\
\text { volume }\end{array}$ & $\begin{array}{l}\text { Inter-void } \\
\text { volume }\end{array}$ & $\begin{array}{l}\text { Intra-void } \\
\text { volume }\end{array}$ & $\begin{array}{l}\text { Solids } \\
\text { volume }\end{array}$ & $\begin{array}{l}\text { Vertical } \\
\text { strain: \% }\end{array}$ \\
\hline I & 7.000 & $3 \cdot 300$ & $2 \cdot 700$ & - & - & - & - & - \\
\hline 34 & $4 \cdot 243$ & 1.922 & $1 \cdot 322$ & 6.851 & $3 \cdot 103$ & $2 \cdot 134$ & $3 \cdot 748$ & $15 \cdot 4$ \\
\hline 65 & $3 \cdot 737$ & 1.668 & 1.068 & 6.033 & 2.694 & $\mathrm{I} \cdot 725$ & 3.339 & $25 \cdot 5$ \\
\hline 120 & $3 \cdot 257$ & 1.429 & 0.829 & 5.259 & $2 \cdot 307$ & 1.338 & 2.953 & 35.0 \\
\hline $24 I$ & $2 \cdot 712$ & $|\cdot| 56$ & 0.556 & $4 \cdot 379$ & 1.867 & 0.898 & 2.513 & 45.9 \\
\hline 463 & $2 \cdot 202$ & 0.901 & 0.301 & 3.555 & 1.455 & 0.486 & $2 \cdot 100$ & $56 \cdot 1$ \\
\hline
\end{tabular}

void volume change, and vertical strains under different stresses would be identical to those of case 1 as they are representing the combined effect of inter- and intra-voids and hence they are not repeated.

\section{DISCUSSION}

The proposed MSW phase relationship was evaluated by applying it to 1D compression data (sample DM3) reported by Powrie and Beaven (1999). The 1D compression analysis showed that the analysis results are comparable to the test results for two cases with assumed different proportions of open intra-voids. The evaluation demonstrated that the proposed phase relationship is capable of analysing total volume losses regardless of the proportions of inter- and intra-voids in the material. It should be noted that the proportion of open intra-voids was only an assumed value in the analysis as this is not available in the test data. Measurements of the proportion of open intra-voids are therefore recommended in future work in order to validate the approach.

In addition to the conventional soil phase relationship, the MSW phase relationship has the function to characterise volume changes from the voids between (inter) and within (intra) the solid particles, which has been demonstrated in the 1D compression analysis. Currently, both inter and intra volume losses have been assumed to be linear with the vertical stresses (logarithm). The total volume loss is bound to be also linear as it is obtained by summing the two volume losses. It appears that the new phase relationship is not beneficial to $1 \mathrm{D}$ compression analysis (e.g. landfill settlement analysis) since it only concerns the total volume loss, which can be modelled linearly. This is true only when both volume losses (induced by inter- and intra-void

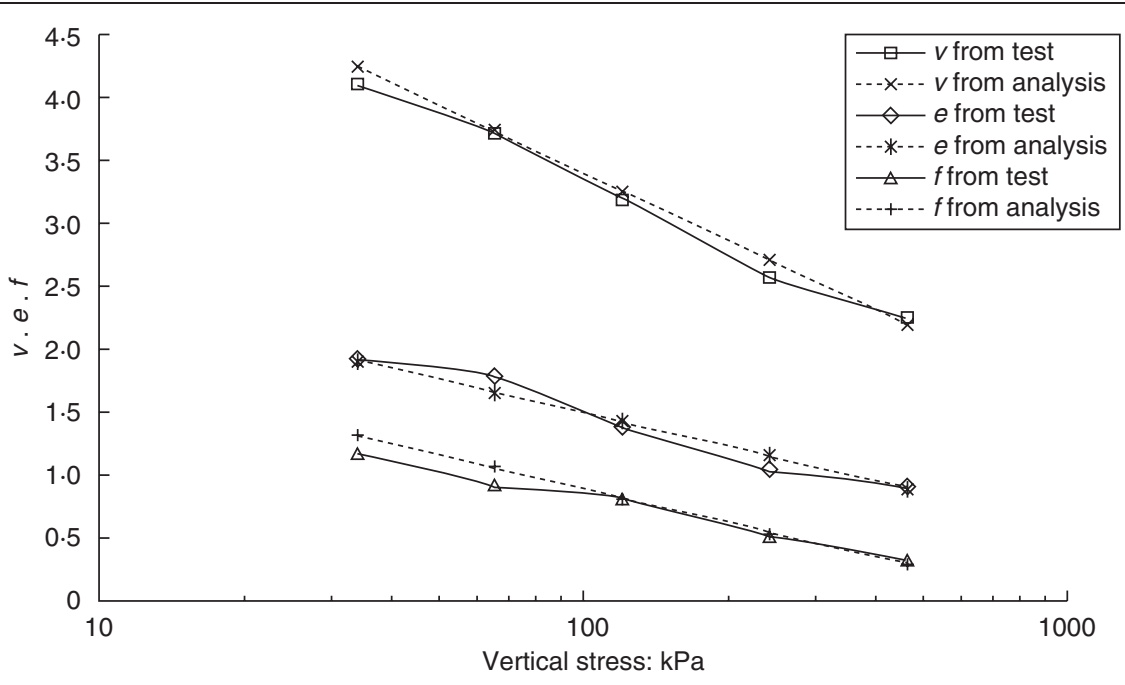

Figure 8. Specific volume, inter-void ratio, intra-void ratio under different vertical stresses obtained from test and ID compression analysis for case 2 
compression) are linear to stress changes. Non-linearity may exist for one or both the volume losses, in which case inter- and intravoids do need to be analysed separately.

More experimental studies are required to investigate the compressive behaviour of inter- and intra-voids of MSW material. The MSW classification system proposed by Dixon and Langer (2006) could be helpful in identifying and separating compressible particles in the experimental studies so that the volumetric proportion of the intra-voids and their compressive behaviour can be investigated. As soon as the compressible particles are isolated, it is not very difficult to determine the parameters that represent the compressive behaviour of both inter- and intra-voids in MSW.

The phase relationship for decomposable soils proposed by McDougall and Pyrah (2004) considered volume loss due to degradation and consequently its effect on time-dependent compressive behaviour of decomposable soils (e.g. organic soils and MSW). The MSW phase relationship proposed in this paper has focused on modelling the transient compressive behaviour of MSW influenced by its compressible particles. There is the potential to combine these two phase relationships when investigating both the transient and time-dependent mechanical behaviour of MSW (i.e. constitutive modelling of MSW).

The MSW phase relationship is important when developing a constitutive model for MSW. It has been suggested that MSW material should be modelled using elasto-plastic constitutive relationships (Machado et al., 2002; Zhang, 2007). A typical elasto-plastic constitutive model needs to define a flow rule that governs dilatancy effects and consequently has a significant influence on the coupled volumetric and shear behaviour. Zhang (2007) pointed out that for MSW material only volume change due to particle movement and rearrangement (i.e. intervoid volume change defined in this paper) should be coupled with its shear behaviour and therefore the volume change due to compression of particles (i.e. intra-void volume change defined in this paper) should be isolated before an analysis of the coupled behaviour. Therefore, the MSW phase relationship could be a fundamental part of any elasto-plastic constitutive model for MSW.

\section{CONCLUSIONS}

The compressive behaviour of MSW has been investigated based on 1D compression testing. Volume loss from the compressible particles has been considered as one of the most important aspects that affect MSW compressive behaviour. A MSW phase relationship has been developed to include the volume loss of compressible particles. Total volume loss in MSW compression is considered from not only the compression of voids between particles (defined as inter-voids) but also the compression of voids within particles (intra-voids). Equations applying the MSW phase relationship to 1D compression have been developed. The MSW phase relationship has been evaluated by undertaking a compression analysis for a 1D compression test and comparing analytical and test results. Based upon reported studies on MSW compression behaviour and the developed phase relationship, the following conclusions can be drawn.

(a) Volume loss of solid particles identified in compression tests and the non-linearity between void ratio changes and vertical stress changes imply that the traditional definition of void ratio in soil mechanics theory may no longer be applicable for MSW material. Relevant amendments are required to include the influence of compressible particles on MSW compressive behaviour.

(b) Inter- and intra-void volumes of an MSW sample (Powrie and Beaven, 1999) under different vertical stresses are dependent on the status of the intra-voids (either open or closed). They can be calculated by assuming the proportions of open or closed intra-voids.

(c) Comparison of analytical and test results demonstrated that the proposed MSW phase relationship is capable of reproducing total volume losses regardless of the proportions of inter- and intra-voids in the material. Measurements of the proportions of inter- and intra-voids are recommended in future work.

(d) The MSW phase relationship may not be beneficial in settlement analysis due to the linearity of both inter- and intra-volumetric changes to stress changes. However, it is important when developing a constitutive model for MSW as an elasto-plastic material.

\section{REFERENCES}

Bryne RJ (1994) Design issues with strain softening interfaces in landfill liners. Proceedings of Waste Tech '94: Landfill Technology, Charleston, South Carolina. National Solid Wastes Management Association, Washington DC, USA, pp. 1-26.

Dixon N and Langer U (2006) Development of a MSW classification system for the evaluation of mechanical properties. Waste Management 26(3): 220-232.

Dixon N, Langer U and Gotteland P (2008) Classification and mechanical behaviour relationships for municipal solid waste: study using synthetic wastes. ASCE Journal of Geotechnical and Geoenvironmental Engineering 134(1): 79-90.

Dixon N, Ng'Ambi S and Jones DRV (2004) Structural performance of a steep slope landfill lining system. Proceedings of the Institution of Civil Engineers, Geotechnical Engineering 157(3): 115-126.

Edil TB, Ranguette VJ and Wuellner WW (1990) Settlement of municipal refuse. In Geotechnics of Waste Fill - Theory and Practise (Landva AO and Knowles GD (eds)). ASTM, Philadelphia, PA, pp. 225-239.

Eid HT, Stark TD, Evans WD and Sherry PE (2000) Municipal solid waste slope failure I: waste and foundation soil properties. ASCE Journal of Geotechnical and Geoenvironmental Engineering 126(5): 397-407.

Filz GM, Esterhuizen JJB and Duncan JM (2001) Progressive failure of lined waste impoundments. ASCE Journal of Geotechnical and Geoenvironmental Engineering 127(10): 841-848.

Fowmes G, Zhang B, Dixon N, El-Hamalawi A and Jones DRV (2005) Modelling waste/barrier interaction. Proceedings of International Workshop on Hydro-Physico-Mechanics of Landfills, Grenoble. Grenoble University, France, CD.

Jones DRV and Dixon N (2005) Landfill lining stability and integrity: the role of waste settlement. Geotextiles and Geomembranes 23(1): 27-53.

Landva AO and Clark JI (1990) Geotechnics of waste fill theory and practice. Geotechnics of Waste Fill - Theory and Practise (Landva AO and Knowles GD (eds)). ASTM, Philadelphia, PA, pp. 86-103. 
Landva A0, Valsangkar AJ and Pelkey SG (2000) Lateral earth pressure at rest and compressibility of municipal solid waste. Canadian Geotechnical Journal 37(6): 1157-1165.

Langer U (2006) Shear and Compression Behaviour of Undegraded Municipal Solid Waste. PhD thesis, Loughborough University.

Ling HI, Leschchnsky D, Mohri I and Kawabata T (1998) Estimation of municipal solid waste landfill settlement. ASCE Journal of Geotechnical and Geoenvironmental Engineering 124(1): 21-28.

Long JH, Gilbert RB and Daly JJ (1995) Effect of waste settlement on sloped lining systems. Proceedings of Geosynthetics '95 Conference, Nashville. International Geosynthetics Society, South Carolina, USA, pp. 729-744.

Machado SL, Carvalho FM and Vilar OM (2002) Constitutive model for municipal solid waste. ASCE Journal of Geotechnical and Geoenvironmental Engineering 128(11): 940-951.

McDougall JR and Hay J (2005) Hydro-bio-mechanical modelling of landfilled waste: formulation and testing. Proceedings of International Workshop on Hydro-PhysicoMechanics of Landfills, Grenoble. Grenoble University, France, CD.

McDougall JR and Pyrah IC (2004) Phase relations for decomposable soils. Géotechnique 54(7): 487-494.
Meißner H and Abel K (2000) Numerical investigations of inclined landfill liner systems. Proceedings of GeoEng 2000, an International Conference on Geotechnical and Geological Engineering, Melbourne. Australian Geomechanics Society, St Ives, New South Wales, Australia.

Powrie W and Beaven RP (1999) Hydraulic properties of household waste and implications for landfills. Proceedings of the Institution of Civil Engineers, Geotechnical Engineering 137(4): 235-247.

Reddy KR, Klsagi S and Motan ES (1996) Interface shear behaviour of landfill composite liner systems: a finite element analysis. Geosynthetics International 3(2): 247-275.

Singh S and Murphy BJ (1990) Evaluation of the stability of sanitary landfills. In Geotechnics of Waste Fill - Theory and Practise (Landva AO and Knowles GD (eds)). ASTM, Philadelphia, PA, pp. 240-258.

Taylor DW (1948) Fundamentals of Soil Mechanics. Wiley, New York.

Zhan LT, Chen YM and Ling WA (2008) Shear strength characterization of municipal solid waste at the Suzhou landfill, China. Engineering Geology 97(3-4): 97-111.

Zhang B (2007) Constitutive Modelling of Municipal Solid Waste. PhD thesis, Loughborough University.

\section{What do you think?}

To discuss this paper, please email up to 500 words to the editor at journals@ice.org.uk. Your contribution will be forwarded to the author(s) for a reply and, if considered appropriate by the editorial panel, will be published as a discussion in a future issue of the journal.

Proceedings journals rely entirely on contributions sent in by civil engineering professionals, academics and students. Papers should be 2000-5000 words long (briefing papers should be 1000-2000 words long), with adequate illustrations and references. You can submit your paper online via www.icevirtuallibrary.com/content/journals, where you will also find detailed author guidelines. 